\title{
Aerobic Oxidation of Benzyl Alcohol in a Continuous Catalytic Membrane Reactor
}

\author{
Achilleas Constantinou ${ }^{1,2} \cdot$ Gaowei Wu$^{2} \cdot$ Baldassarre Venezia $^{2} \cdot$ Peter Ellis $^{3} \cdot$ Simon Kuhn ${ }^{4} \cdot$ Asterios Gavriilidis $^{2}$
}

Published online: 20 October 2018

(c) The Author(s) 2018

\begin{abstract}
A catalytic membrane reactor with a Au-Pd catalyst, impregnated at the inner side of the membrane, was studied in the catalytic oxidation of benzyl alcohol in flow. The reactor comprised of four concentric sections. The liquid substrate flowed in the annulus created by an inner tube and the membrane. The membrane consisted of 3 layers of $\alpha$-alumina and a titania top layer with $5 \mathrm{~nm}$ average pore size. Oxygen was fed on the outer side of the membrane, and its use allowed the controlled contact of the liquid and the gas phase. Experiments revealed excellent stability of the impregnated membrane and selectivities to benzaldehyde were on average $>95 \%$. Increasing the pressure of the gas phase and decreasing liquid flowrates and benzyl alcohol concentration resulted in an increased conversion, while selectivities to benzaldehyde remained constant and in excess of $95 \%$.
\end{abstract}

Keywords Gold/palladium catalyst $\cdot$ Catalytic oxidation $\cdot$ Continuous flow $\cdot$ Membrane reactor $\cdot$ Ceramic membrane

\section{Introduction}

High value chemicals are generally produced in batch reactors, generally leading to the generation of a large amount of waste and less control over the reaction parameters [1]. Continuous processing might therefore represent a valuable alternative [2]. Oxidation of alcohols is a reaction of great interest in the chemical industry and products like aldehydes and ketones are used for the manufacture of fragrances and intermediates [3]. Oxidation of alcohols is typically achieved by inorganic oxidants which are toxic and not environmentfriendly. Therefore, heterogeneously catalysed aerobic oxidations of alcohols have recently attracted attention [4-9].

Asterios Gavriilidis

a.gavriilidis@ucl.ac.uk

1 Division of Chemical and Petroleum Engineering, School of Engineering, London South Bank University, London SE1 OAA, UK

2 Department of Chemical Engineering, University College London, Torrington Place, London WC1E 7JE, UK

3 Johnson Matthey Technology Centre, Blount's Court, Sonning Common, Reading RG4 9NH, UK

4 Department of Chemical Engineering, KU Leuven, W. de Croylaan 46, 3001 Leuven, Belgium
Membrane contactors have drawn interest due to the possibility of integrating a separation and a reaction unit in a single module $[10,11]$. Membranes are commonly used in various processes such as extraction, absorption and stripping [12-14]. The use of ceramic membrane as catalytic reactors dates back in the 1980s and has been applied when chemical harsh environments and high temperatures are involved [15]. The membranes typically have a structure which comprises a support layer, generally made of alumina with large pores, that can guarantee mechanical strength and high permeability, and a thin layer made of a different material which controls the diffusive flux [15]. As contactor the catalytic membrane reactor (CMR) provides a well-defined interface between the two separated phases, and allows to have an independent control of the reactant flow rates during reaction $[11,16]$. In heterogeneous catalytic processes, the CMR can be either used to contain a packed-bed catalyst, or as support for the deposition of a catalyst on the inner side of the membrane $[15,17]$.

In our recent work, we investigated benzyl alcohol oxidation in flow using a ceramic membrane packed-bed reactor with a Au-Pd/TiO ${ }_{2}$ catalyst [18]. The role of the membrane was to provide an interface for the gas and the liquid phase to contact each other without letting one phase breaking through the adjacent one. This could be achieved by feeding pure oxygen from the outer surface of the membrane at 
a higher pressure than the liquid which flowed in the membrane's bore through the packed bed region. The same reaction was performed using a Teflon AF-2400 tube-in-tube reactor [19]. The Au-Pd/TiO ${ }_{2}$ catalyst was packed in the inner tube where the liquid flowed, while oxygen was fed in the annulus between the inner and the outer tube. It was found that conversion was significantly improved as compared to a reactor where oxygen was pre-saturated before entering the reactor. The main advantages of the membrane packed-bed reactor is the capability of keeping the gas and the liquid phase separated and of exchanging catalyst in case of deactivation. However, mass transfer resistances can present a drawback for fast reactions. A way to overcome this limitation is the use of a catalytic membrane reactor.

In the catalytic membrane configuration the gas is directly supplied to the catalytic region, hence reducing mass transfer resistances. Vospernik et al. [20] performed experimental studies with a ceramic membrane reactor for the hydrogenation of nitrite ions to nitrogen. The membrane was impregnated with metallic palladium using an incipient wetness impregnation technique. It was demonstrated that the position of the gas/liquid interface within the membrane wall is one of the most important parameters for the overall performance of the ceramic three phase membrane reactor. Pashkova et al. [21] used different membranes for the direct synthesis of hydrogen peroxide. The membrane materials were $\mathrm{Al}_{2} \mathrm{O}_{3}, \mathrm{TiO}_{2}$, and carbon coated $\mathrm{Al}_{2} \mathrm{O}_{3}$ with a Pd catalyst deposited into the finest porous layer on the inner side of the membrane. Oxygen was fed from the outer side of the membrane module while hydrogen was dissolved at high pressure in the liquid. It was shown that the diffusive transport of the reactants to the catalytically active zone located on the inner walls of the membrane channel was critical.

Few studies investigated the catalytic oxidation of benzyl alcohol under flow conditions using Au/Pd catalyst [5, $22,23]$. Aerobic catalytic oxidations are usually avoided in industry due to safety concerns. In this work, benzyl alcohol oxidation in a catalytic membrane reactor under flow conditions was studied. The Au/Pd catalyst was impregnated on the inner side of the ceramic membrane, hence the gas phase can be supplied directly to the catalyst region. This can potentially reduce the mass transfer resistances encountered in packed-bed membrane reactors. Moreover, this configuration where the oxidant is added continuously along the length of the reactor offers safer operation compared to batch slurry systems since gas/liquid flammable mixtures are avoided.

\section{Experimental}

\subsection{Ceramic Membrane Preparation and Characterisation}

A commercial ceramic membrane tube (Pall, Europe) with a length of $75 \mathrm{~mm}$, outside diameter (O.D.) $10 \mathrm{~mm}$ and inside diameter (I.D.) $7 \mathrm{~mm}$ was used. The membrane consisted of 3 layers of $\alpha$-alumina and a titania top layer of $5 \mathrm{~nm}$ pore size with a thickness of around 14-20 $\mu \mathrm{m}$ (see Fig. 1). The Au-Pd catalyst was deposited on the inner $\mathrm{TiO}_{2}$ layer by impregnation of a precursor solution. The solution was made of $0.332 \mathrm{~mL} \mathrm{HAuCl} \mathrm{H}_{4} \cdot 3 \mathrm{H}_{2} \mathrm{O}$ (Sigma-Aldrich) containing $2 \mathrm{mg} \mathrm{Au}, 38 \mathrm{mg}$ of $\mathrm{PdCl}_{2}$ (Sigma-Aldrich) containing $23 \mathrm{mg}$ $\mathrm{Pd}$ and $4 \mathrm{~mL}$ of deionized water. The mixture was sonicated and heated (ca. $50{ }^{\circ} \mathrm{C}$ ) up to $10 \mathrm{~min}$ using an ultrasonic bath (UW). The resulting homogeneous solution was then injected into the membrane's bore and by rotating the membrane horizontally using a rotating device, the membrane was impregnated with the precursor solution, while the solution evaporated. It was subsequently dried at $110^{\circ} \mathrm{C}$ for $16 \mathrm{~h}$ and calcined at $400{ }^{\circ} \mathrm{C}$ for $2 \mathrm{~h}$. After reaction, the membrane was scraped from the inner side and a TEM analysis (Tecnai
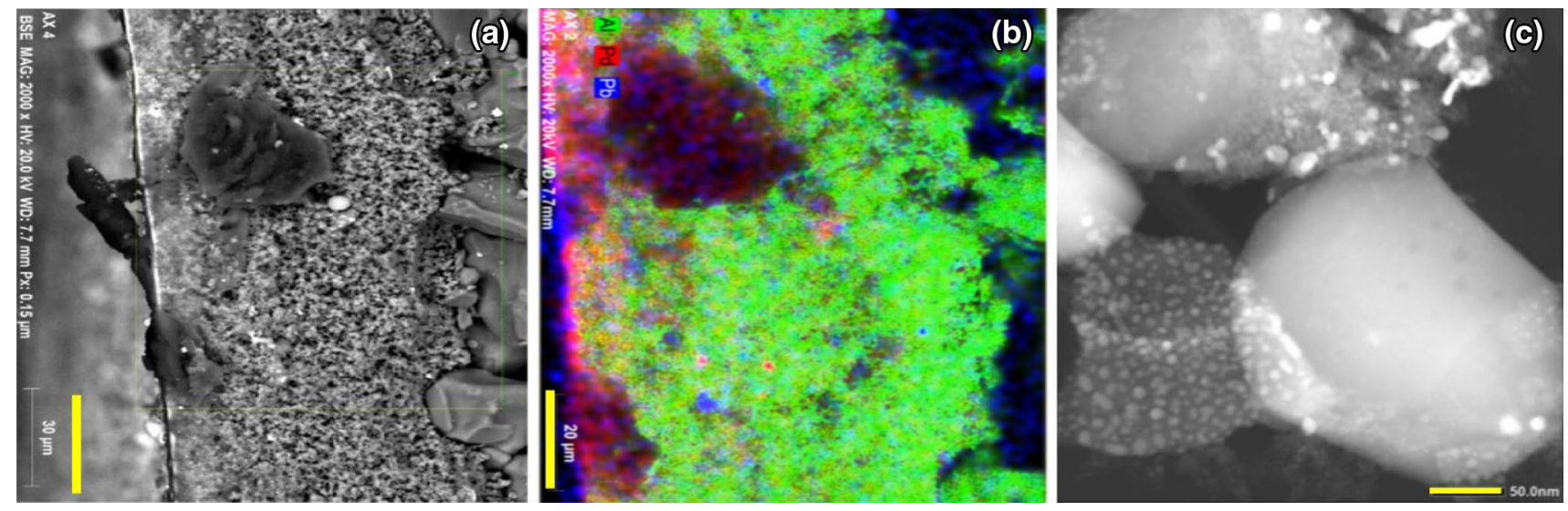

Fig. 1 a SEM image of the cross section of membrane. b EDX mapping $\mathbf{c}$ TEM image of a scraped part of the inner side of the membrane. Green colour indicates $(\mathrm{Al})$, red colour $(\mathrm{Pd})$ and blue colour $(\mathrm{Pb})$ 
F20, $200 \mathrm{kV}$ ) was performed to observe the metal particle size. Figure 1c shows that the particle size was around 5-20 nm. However, the presence of smaller particles cannot be excluded. An elemental scan of the membrane was also performed $(20 \mathrm{kV}$, Zeiss ultra 55). The analysis indicated that Pd was mainly concentrated at the top thin layer of titania (Fig. 1a\&b). Small amount of lead was also observed on the membrane analysis; the cause of this is not clear but it may have originated from impurities in the membrane.

\subsection{Catalytic Membrane Reactor Set-up}

The reactor comprised four concentric sections (see Fig. 2a). The inner tube (where a thermocouple was placed), created an annulus with the ceramic membrane, in which glass beads (particle size 100-200 $\mu \mathrm{m}$ ) were packed. These were used to improve the liquid flow. Outside the membrane, oxygen was pressurised by means of a gas pressure regulator (Swagelok, U.S). The experimental setup is similar to our previous set-up used for the catalytic oxidation of benzyl alcohol in a packed-bed membrane reactor [18]. The differences for this particular set-up are that oxygen was pressurized and the reactor was shorter $(7.5 \mathrm{~cm}$ compared to $25 \mathrm{~cm})$. In addition, an extra thermocouple was placed inside the inner tube, which enabled temperature measurements at different locations along the reaction area. The temperature difference between the two ends of the catalytic membrane was $\pm 2.5^{\circ} \mathrm{C}$. To avoid breakthrough of one phase into the other the reactor was operated with a pressure difference between the gas and the liquid phase $\mathrm{P}_{\mathrm{G}}-\mathrm{P}_{\mathrm{L}} \approx 0.1$ bar. After the system stabilized at the desired temperature and pressures, sample collection started. The liquid flow rate varied in the range $0.005-0.04 \mathrm{ml} / \mathrm{min}$, while the gas phase pressure varied from 2 to 5 bara and the reaction temperature was kept at an average value of $115^{\circ} \mathrm{C}$.

Benzyl alcohol conversion (X) and product selectivity (S) were calculated based on the following equations:

$X=\frac{C_{\text {alcohol,in }}-C_{\text {alcohol,out }}}{C_{\text {alcohol,in }}} \times 100 \%$

where $C_{\text {alcohol,in }}$ and $C_{\text {alcohol,out }}$ were the concentration of benzyl alcohol at the inlet and outlet, respectively,

$S_{i}=\frac{C_{i} \cdot v_{i}}{C_{\text {alcohol, } i n} \cdot X_{\text {total }}} \times 100 \%$

where $\nu_{i}$ was the number of moles of benzyl alcohol consumed for the production of $1 \mathrm{~mol}$ of product $i$.

Reproducibility of the experiments and catalyst stability were checked by a standard run $\left(115^{\circ} \mathrm{C}\right.$, liquid flowrate $0.02 \mathrm{ml} / \mathrm{min}$, gas pressure $3 \mathrm{bara}$ ) every day, and the relative differences in conversion between the standard runs was less than $\pm 5 \%$. (a)

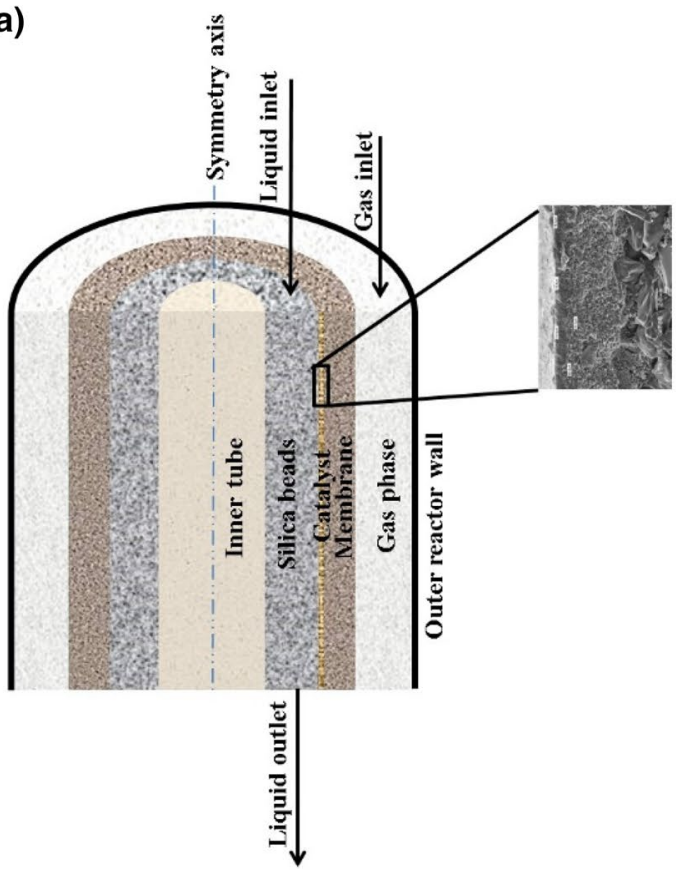

(b)

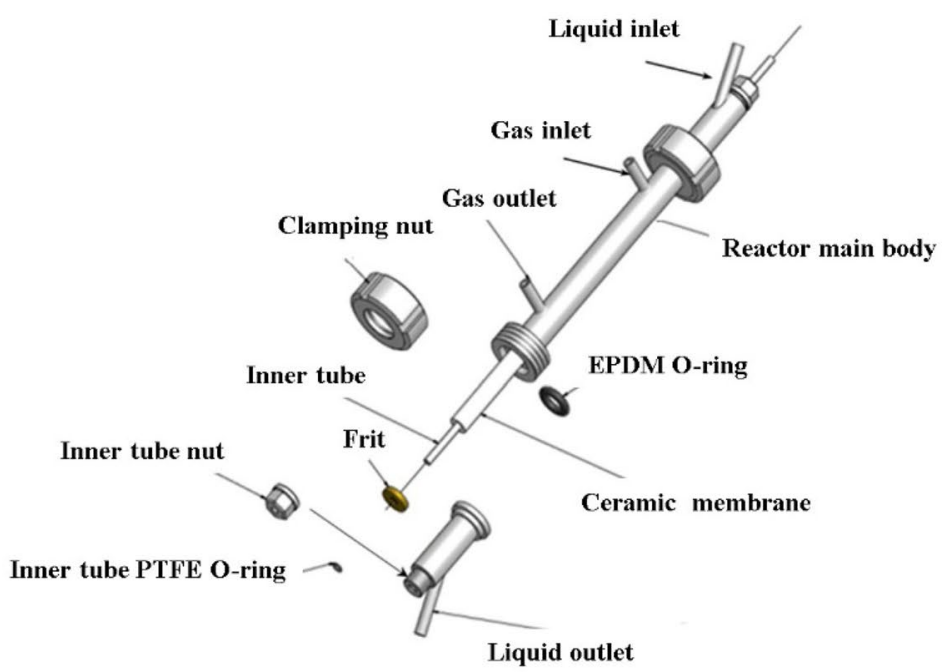

Fig. 2 Schematics of the membrane reactor: a cross section of the reactor with an SEM picture of the catalytic membrane, b components of the reactor 
Fig. 3 Stability test of the catalytic membrane reactor. Reaction conditions: liquid flowrate $=0.01 \mathrm{ml} / \mathrm{min}$, gas pressure 3 bara, $25 \mathrm{mg} \mathrm{Au} / \mathrm{Pd}$, inlet pure benzyl alcohol, reactor temperature $\sim 115^{\circ} \mathrm{C}$

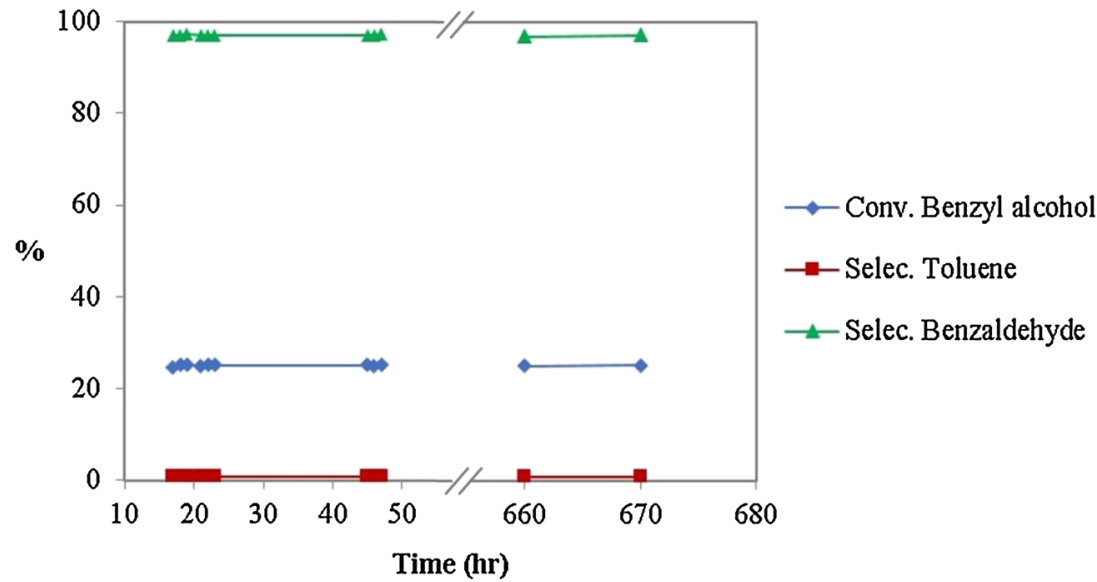

\section{Results and Discussion}

\subsection{Stability of the Catalytic Membrane}

Figure 3 shows the stability test performed for the catalytic membrane over a period of $670 \mathrm{~h}$. Conversion of benzyl alcohol was stable during that period and it was $\sim 25 \%$ while the selectivity to benzaldehyde was $\sim 97 \%$ and remained stable as well. In contrast, in our previous work [18] a similarly prepared $\mathrm{Pd}-\mathrm{Au} / \mathrm{TiO}_{2}$ catalyst that was used as a packed bed showed lower selectivity after being active for 4-5 days. The high selectivity to benzaldehyde obtained in this work might be due to improved oxygen mass transfer to the catalytic sites. Oxygen did not have to diffuse through the liquid film inside the pores of the ceramic membrane in order to reach the catalyst region as it was happening with the packed-bed membrane reactor but it was supplied directly to the catalyst region, resulting in an improved and increased oxygen mass transfer. We cannot exclude the possibility that the adventitious presence of lead affected the selectivity.

\subsection{Effect of Benzyl Alcohol Flowrate}

The effect of liquid flow rate was studied by varying the benzyl alcohol flowrate from 0.005 to $0.040 \mathrm{~mL} / \mathrm{min}$. Figure 4 shows that benzyl alcohol conversion increased up to $40 \%$ for $0.005 \mathrm{~mL} / \mathrm{min}$, while selectivity of benzaldehyde was nearly constant $\sim 93-97 \%$. By decreasing the liquid flowrate the liquid residence time increased and as a result oxygen had more time to diffuse and react, thus benzyl alcohol conversion increased. Because of the high availability of $\mathrm{O}_{2}$ at the catalytic sites due to high $\mathrm{O}_{2}$ mass transfer, the selectivity to the oxidation reaction was high and nearly constant. In our previous work [18], where benzyl alcohol oxidation was performed in a packed-bed membrane reactor, conversion and selectivities to benzaldehyde increased by increasing the catalyst contact time since oxygen had more time to permeate and react.

\subsection{Effect of Oxygen Pressure}

In order to increase the oxygen availability for the reaction, gas pressure was varied from 2 to 5 bara (Fig. 5) while the liquid flowrate was kept at $0.040 \mathrm{~mL} / \mathrm{min}$. Benzyl alcohol conversion increased up to $20 \%$, while benzaldehyde selectivity changed slightly between $92-97 \%$. Increasing the gas pressure leads to an increase of the dissolved oxygen concentration. As a result more oxygen was available for the reaction and hence benzyl alcohol conversion increased. Similar results were observed in our previous work [19], where a tube-in-tube configuration was used, and it was found that conversion and benzaldehyde selectivity increased by increasing the gas pressure from 3 to 7 bara due to increased oxygen permeation.

\subsection{Effect of Catalyst Amount and Benzyl Alcohol Dilution}

To study the effect of catalyst amount a catalytic membrane was fabricated using the same method as described in Sect. 2.1 but using 5 times less catalyst amount $(5 \mathrm{mg} \mathrm{Au} /$ Pd) compared to previous experiments $(25 \mathrm{mg} \mathrm{Au} / \mathrm{Pd})$. In addition, to observe the effect of benzyl alcohol concentration on benzyl alcohol conversion experiments were performed by diluting benzyl alcohol with o-xylene. Comparing the results obtained for a catalyst amount of $5 \mathrm{mg}$ and $2 \mathrm{M}$ benzyl alcohol with the results obtained for a catalyst amount of $25 \mathrm{mg}$ and pure benzyl alcohol, it is observed that the conversion of benzyl alcohol, the selectivity to benzaldehyde and the average reaction rate were nearly the same (see Table 1). In addition to decreasing the catalyst amount by a factor of 5 , the benzyl alcohol concentration was decreased 5 times as well, which reduced the demand of oxygen for the reaction. Since the same reaction rates 
Fig. 4 Effect of benzyl alcohol flowrate on benzyl alcohol conversion and selectivities to toluene and benzaldehyde. Reaction conditions: gas pressure 3 bara, $25 \mathrm{mg} \mathrm{Au} / \mathrm{Pd}$, inlet pure benzyl alcohol, reactor temperature $\sim 115^{\circ} \mathrm{C}$
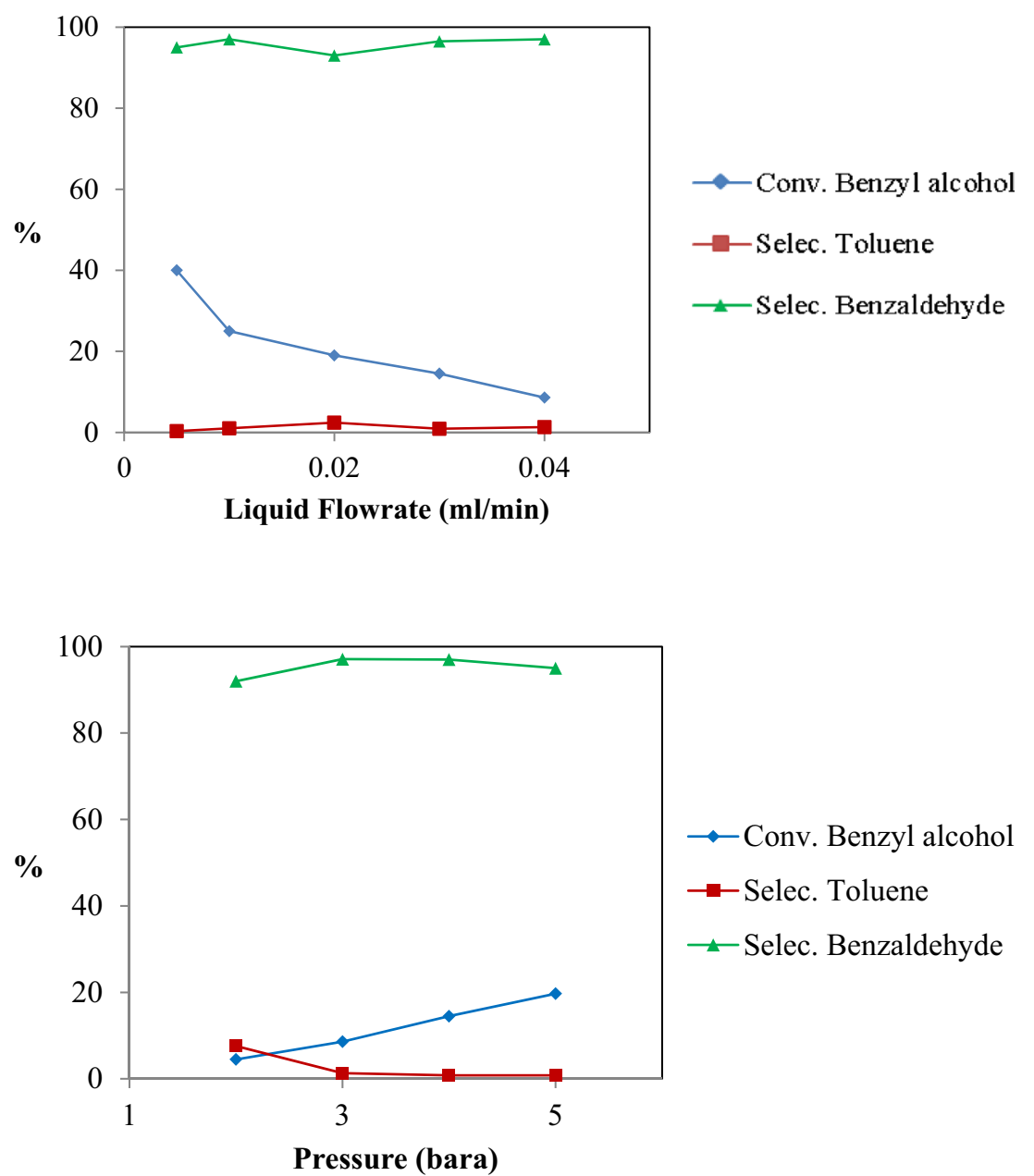

Pressure (bara)
Fig. 5 Effect of pressure on benzyl alcohol conversion and selectivities to toluene and benzaldehyde. Reaction conditions: liquid flowrate $=0.04 \mathrm{ml} /$ $\min , 25 \mathrm{mg} \mathrm{Au} / \mathrm{Pd}$, inlet pure benzyl alcohol, reactor temperature $\sim 115^{\circ} \mathrm{C}$

Table 1 Effect of catalyst amount and benzyl alcohol concentration on benzyl alcohol conversion and benzaldehyde selectivity

\begin{tabular}{llllccc}
\hline Catalyst amount (mg) & $\begin{array}{l}\text { Conc. of } \\
\text { benzyl alcohol (M) }\end{array}$ & $\mathrm{X} \%$ & $\mathrm{~S}_{\text {Benzaldehyde }} \%$ & $\mathrm{~S}_{\text {Toluene }} \%$ & $\begin{array}{l}\text { Average reaction rate } \\
\left(\mathrm{mol} / \mathrm{min} \cdot \mathrm{g}_{\text {cat }}\right)\end{array}$ \\
\hline 25 & 9.6 & 19 & 93 & 3 & $1.4 \times 10^{-6}$ & $\begin{array}{c}\text { Temp. }\left({ }^{\circ} \mathrm{C}\right) \\
25\end{array}$ \\
5 & 0.5 & 61 & 95 & 3 & $4.3 \times 10^{-7}$ & 115 \\
$\begin{array}{l}4.4 \text { Packed bed membrane } \\
\text { reactor [18] }\end{array}$ & 0.5 & 19 & 94 & 9 & $1.42 \times 10^{-6}$ & $1.5 \times 10^{-6}$ \\
\hline
\end{tabular}

Reaction conditions: gas pressure 3 bara, liquid flowrate $0.02 \mathrm{ml} / \mathrm{min}$. The rest of the products were benzene, dibenzyl ether, benzoic acid and benzyl benzoate with their selectivities always $<4 \%$

Average reaction rate $=\mathrm{F}_{1} \cdot \mathrm{C}_{\mathrm{BzOH}} \cdot \mathrm{X} \cdot \mathrm{S}_{\text {Benzaldehyde }} / \mathrm{g}_{\text {cat }}$, where $\mathrm{X}=$ conversion of benzyl alcohol, $\mathrm{F}_{\mathrm{l}}=$ liquid flow rate, $\mathrm{S}_{\mathrm{Benzaldehyde}}=$ selectivity to benzaldehyde

were observed, this suggests that mass transfer resistances were not present. Furthermore, experiments performed with the catalytic membrane of $25 \mathrm{mg} \mathrm{Au} / \mathrm{Pd}$ loading and benzyl alcohol concentration of $0.5 \mathrm{M}$ showed an increased conversion of benzyl alcohol of $61 \%$ as compared to $2 \mathrm{M}$ benzyl alcohol and $5 \mathrm{mg}$ catalyst amount, while selectivity to benzaldehyde was almost the same at $95 \%$. Since, in this case the benzyl alcohol/catalyst ratio was smaller, higher conversion was achieved. Comparison of reaction rates in this case must be done with caution, as the conversion was high. When compared to the membrane packed bed reactor in our previous work [18], for the same inlet benzyl alcohol concentration of $0.5 \mathrm{M}$, the catalytic membrane showed higher selectivity, which is attributed to more efficient mass 
transfer. The lower average reaction rate observed may be due to the relatively high particle size $4-20 \mathrm{~nm}$, as compared to the catalyst used in the membrane packed bed reactor, which was 1-2 nm.

\section{Conclusions}

A catalytic ceramic membrane impregnated with a $\mathrm{Au}-\mathrm{Pd}$ catalyst in its inner surface was developed and used for the continuous heterogeneously catalysed aerobic oxidation of benzyl alcohol. The catalytic membrane reactor showed excellent stability over a period of $670 \mathrm{~h}$. Increasing pressure and decreasing liquid flowrate led to an increased conversion of benzyl alcohol, while the selectivity to benzaldehyde was nearly constant at $>95 \%$. Diluting the benzyl alcohol, conversion was increased with nearly constant selectivity to benzaldehyde. The catalytic ceramic membrane showed high selectivity to benzaldehyde, possibly due to improved oxygen mass transfer to the catalyst compared to our previous studies where a packed-bed membrane reactor was used. This configuration allows safer operation than the batch mode, since the gas phase does not come in direct contact with the organic mixture.

Acknowledgements Funding for this work was provided by EPSRC Grant EP/L003279/1. We would like to thank G. Goodlet from Johnson Matthey for the SEM and TEM measurements.

Open Access This article is distributed under the terms of the Creative Commons Attribution 4.0 International License (http://creativeco mmons.org/licenses/by/4.0/), which permits unrestricted use, distribution, and reproduction in any medium, provided you give appropriate credit to the original author(s) and the source, provide a link to the Creative Commons license, and indicate if changes were made.

\section{References}

1. Wiles C, Watts P (2012) Continuous flow reactors: a perspective. Green Chem 14:38-54

2. Gavriilidis A, Constantinou A, Hellgardt K, Hii KK, Hutchings JG, Brett G, Kuhn S, Marsden PS (2016) Aerobic oxidations in flow: opportunities for the fine chemicals and pharmaceuticals industries. Reac Chem Eng 1:595-612

3. Hudlicky M (1990) Oxidations in Organic Chemistry. American Chemical Society, Washington, DC

4. Mallat T, Baiker A (2004) Oxidation of alcohols with molecular oxygen on solid catalysts. Chem Rev 104(6):3037-3058

5. Wang N, Matsumoto T, Ueno M, Miyamura H, Kobayashi S (2009) A gold-immobilized microchannel flow reactor for oxidation of alcohols with molecular oxygen. Angew Chem 121:4838-4840
6. Zotova N, Hellgardt K, Kelsall GH, Jessiman AS, Hii KK (2010) Catalysis in flow: the practical and selective aerobic oxidation of alcohols to aldehydes and ketones. Green Chem 12:2157-2163

7. Kesavan L, Tiruvalam R, Rahim MHA, Bin Saiman MI, Enache DI, Jenkins RL, Dimitratos N, Lopez-Sanchez JA, Taylor SH, Knight DW, Kiely CJ, Hutchings GJ (2011) Solvent-free oxidation of primary carbon-hydrogen bonds in toluene using Au-Pd alloy nanoparticles. Science 331:195-199

8. Obermayer D, Balu AM, Romero AA, Goessler W, Luque R, Kappe CO (2013) Nanocatalysis in continuous flow: supported iron oxide nanoparticles for the heterogeneous aerobic oxidation of benzyl alcohol. Green Chem 15:1530-1537

9. Arends IWCE, Sheldon RA (2010) Modern oxidation of alcohols using environmentally benign oxidants. Modern Oxidation Methods. Wiley, Weinheim, p. 147-185

10. Li K (2007) Ceramic membranes and membrane processes. Ceramic membranes for separation and reaction. Wiley, Hoboken, pp 1-20

11. Vospernik M, Pintar A, Bercic G, Batista J, Levec J (2004) Potentials of ceramic membranes as catalytic three-phase reactors. Chem Eng Res Des 82:659-666

12. Cai ZX, Fang Q, Chen HW, Fang ZL (2006) A microfluidic chip based liquid-liquid extraction system with microporous membrane. Anal Chim Acta 556:151-156

13. Constantinou A, Barrass S, Gavriilidis A (2014) $\mathrm{CO}_{2}$ absorption in polytetrafluoroethylene membrane microstructured contactor using aqueous solutions of amines. Ind Eng Chem Res 53(22):9236-9242

14. Constantinou A, Ghiotto F, Lam KF, Gavriilidis A (2014) Stripping of acetone from water with microfabricated and membrane gas-liquid contactors. Analyst 139:266-272

15. Coronas J, Santamaría J (1999) Catalytic reactors based on porous ceramic membranes. Catal Today 51(3-4):377-389

16. Vospernik M, Pintar A, Levec J (2006) Application of a catalytic membrane reactor to catalytic wet air oxidation of formic acid. Chem Eng Process 45(5):404-414

17. Julbe A, Farrusseng D, Guizard C (2001) Porous ceramic membranes for catalytic reactors-overview and new ideas. J Membr Sci 181(1):3-20

18. Constantinou A, Wu G, Corredera A, Ellis P, Bethell D, Hutchings GJ, Kuhn S, Gavriilidis A (2015) Continuous heterogeneously catalyzed oxidation of benzyl alcohol in a ceramic membrane packed-bed reactor. Org Process Res Dev 19:1973-1979

19. Wu G, Constantinou A, Cao E, Kuhn S, Morad M, Sankar M, Bethell D, Hutchings GJ, Gavriilidis A (2015) Continuous heterogeneously catalyzed oxidation of benzyl alcohol using a tube-intube membrane microreactor. Ind Eng Chem Res 54:4183-4189

20. Vospernik M, Pintar A, Bercic G, Levec J (2003) Experimental verification of ceramic membrane potentials for supporting threephase catalytic reactions. J Membr Sci 223:157-169

21. Pashkova A, Dittmeyer R, Kaltenborn N, Richter H (2010) Experimental study of porous tubular catalytic membranes for direct synthesis of hydrogen peroxide. Chem Eng J 165:924-933

22. Kaizuka K, Lee KaY, Miyamura H, Kobayashi S (2012) Multiphase flow systems for selective aerobic oxidation of alcohols catalyzed by bimetallic nanoclusters. J Flow Chem 2:1-4

23. Cao E, Sankar M, Firth S, Lam KF, Bethell D, Knight DK, Hutchings GJ, McMillan PF, Gavriilidis A (2011) Reaction and Raman Spectroscopic Studies of alcohol oxidation on Gold-Palladium catalysts in microstructured reactors. Chem Eng J 167:734-743 